\title{
Review of Christopher Nobbs's Economics, sustainability, and democracy: economics in the era of climate change. New York: Routledge, 2013, 280 pp.
}

\author{
Paul Dragos Aligica \\ George Mason University
}

This book advances a threefold argument. First, it claims that what the author calls the "libertarian" approach to economics, which flourished in the last part of the 20th century, is "practically and ethically inadequate for the needs of the 21st century". Second, it asserts that although the welfarist economics approach that preceded it has some merits, it has "serious limitations" too. Third, it advances the alternative ideal of "an overarching economics based on ecological principles" (p. xx). This alternative, the author claims, offers an appropriate response to the challenges of the 21st century. In brief, the book is a presentation and criticism of established theories and doctrines, combined with an attempt to sketch the contours of an alternative to them.

Given these objectives, the book has to cover a wide range of literatures, from microeconomics and macroeconomics to institutional economics, and from political economy to ethical (meta-) theory and cutting-edge debates in political philosophy. Its 12 chapters are organized into four parts, each dealing with a set of themes: part I is an overview and criticism of 20th century microeconomics and macroeconomics; part II discusses the relationships between economics, ethics, and ideology; part III deals with the relationships between the economy, society, and the natural world; and part IV discusses economics and the political theory of social justice, democracy, and social deliberation. The breadth of the author's familiarity with the relevant debates and academic literatures is truly impressive. In this respect, the book is an excellent introduction to the state of an entire cluster of disciplines, themes and research programs. Excepting minor slips, the presentations and discussions manage to maintain a neutral and objective stance. (One such slip occurs in chapter 5, on economics and ideology, where the author falls in with the typical routine of identifying the usual ideological suspect, the "Chicago School", while the 
"Keynesian School"-presumably a non-ideological, value-free endeavor that is above suspicion-goes unmentioned.) Overall, the book leaves the reader with a clear and fair map of the thematic and conceptual terrain, and this accomplishment alone is enough to make it both interesting and useful.

As one might expect, in the criticism of theories and schools of thought in the social sciences there is always room for multiple controversial interpretations. Readers trained in different traditions may find some of the critical claims advanced by Nobbs debatable, or they may feel the need for caveats and nuances. Regarding his big-picture critical narrative of the nature and evolution of economic thinking in the 20st century, some readers may consider his interpretation in need of amendments or missing significant elements. For instance, one might wonder whether the approach to economics that flourished in the last part of the 20th century truly deserves the label "libertarian" that Nobbs gives it, and indeed whether anything deserving that label actually flourished in the 20th century. Or one might wonder about the relevance (if any) of the 'public choice' revolution and its contributions to the theory of "government failure". Do the theoretical, empirical and normative arguments advanced by Public Choice scholars have any bearing on (a) our assessment of various competing contemporary schools of political economy and (b) the way we may imagine and construct a new economics in the 21st century?

But these, and similar questions that may be raised from different intellectual and ideological perspectives, are secondary to the assessment of Nobbs's basic thesis. One may quibble over details, one may disagree with this or that interpretation, but the bottom line remains that, whether we like it or not, a change in how we think about the economy is needed. A reorientation of economic theory and practice is necessary because our understanding, concerns, and problems have changed. Global climate change is only one of those changes. The climate of ideas also changes: the other natural and social sciences produce new ways of understanding the world; our social and environmental circumstances change; new challenges emerge; even our ethical and normative beliefs and sensibilities change. So, in the end, economics has to change too.

The question is, in what ways? We have now reached the most interesting question addressed by the book. How should economics be 
conducted in liberal democracies in the 21st century? On what lines should the economics of the future be reconstructed?

Nobbs suggests two dimensions that this reconstruction should incorporate: the ecological and the ethical. The former requires rebuilding economics around the positive scientific observation that human societies are part of the natural world. To analyze and manage the "economy" as one aspect of socio-ecological systems requires understanding the interplay between physical laws and social processes. One has to take that basic reality into account when dealing with economic systems, institutions and policies. The latter requires adding a strong normative dimension to that expanded positive analysis. Ethical questions are deeply embedded in issues of economic governance and sustainability. In the end economics is about human action and decision-making, subjects with a strong ethical dimension. Sooner or later, economics will be forced to engage with this ethical dimension in ways that go beyond the concept of "efficiency". In conjunction, these two dimensions (the positive naturalization of economic systems and the normative endogenization of moral meaning) define the framework within which the reorientation of economic theory and practice for the 21st century should proceed.

What does this foundational reorientation mean in more concrete terms? Nobbs points first to what has been known for some time as "ecological economics", in which the economy is seen as part of natural systems and natural systems are seen as a foundation of economic processes and systems (Sagoff 2012; Constanza 1989). The focus shifts to social-ecological systems, and to complex adaptive systems in general. The central concern is with trying to capture the evolutionary forces that generate adaptive equilibria and the systemic processes associated with the ways the human economy is embedded in ecosystems (Levin 1999). This approach may rightly be seen as a response to the present "fixation on economic efficiency", ignoring "the physical characteristics of material objects" (p. 150).

However, Nobbs also points to another perspective, related to but quite different from ecological economics. Over the last three decades scholars have developed the field of "environmental economics", which takes a perspective firmly based on mainstream micro-economics and welfare theory. Environmental problems are diagnosed as market externalities using a theoretical apparatus centered on "welfare", "utility", and "willingness to pay" as key analytical and policy variables 
(Sagoff 2012; Stavins 2008). In this view, the main focus is not the evolutionary equilibrium of the systems emerging as a result of interactions between humans and nature (as in ecological economics), but calculating the full costs of human activities and supporting decision-making regarding the environment, for example about tradeoffs. Hence the methodological focus on shadow prices and cost-benefit analysis, and the general policy practice of using economics as a science of valuation to estimate and put prices on alternatives, situations and things, including ecosystems.

Both approaches are legitimate. But, unsurprisingly, their basic philosophies, epistemologies, and methodologies differ in nontrivial ways. Predictably, tensions emerge. However, both are alike in offering a view in which the voice of the technocratic, scientific community is not just salient but preeminent when it comes to the policies and interventions deemed desirable. The definitions and solutions of our problems come primarily from the technocratic elite, be they experts in social-ecological systems or in economics. That is to say, those who articulate the basic parameters of the correct or desirable solutions scientifically have a privileged position in the policy process.

But there is yet another perspective in the range of alternatives that have emerged in the last couple of decades, a perspective that departs in substantial ways from those described above, especially when it comes to the policy process. Interestingly enough, Nobbs seems to gravitate toward it, since he ends his book by exploring some of the building blocks of this position.

Let us call this perspective "institutionalist". It is an institutional approach based not on systems ecology or cost-benefit economics but on a theory of values implying an important role for a variety of ethical and aesthetic arguments, besides the economic-efficiency ones. In brief, it is a theory of institutions and governance under conditions of heterogeneity in individuals' values, beliefs, and preferences. The idea is that there are different ways of judging the value of things, whether natural or social. Some things may be seen in pure economic terms; other things should be seen in ethical, aesthetic, or even religious terms. A social-ecological system is not just a complex adaptive system or a welfare or utility generator, but may have many other intrinsic values in the eyes of the members of a community or society. The challenge is how to make collective decisions in such heterogeneous circumstances in which diversity of values, principles and preferences is 
the norm: for instance, how to use ethical frameworks of responsibility in addition to (or as an alternative to) the frameworks of cost-benefit analysis. The institutional approach deals with this challenge by focusing on rulemaking and regulation based on deliberation, public discussion, and negotiation, conducted via democratic processes. Its distinctive feature is the idea of "second-order institutions" (Knight and Johnson 2011) that give voice to stakeholders and create a collective space for deliberation and negotiation. Such "democratic" arrangements offer a chance to incorporate alternative principles quite different from the "willingness to pay" principle or what the technocratic elite may suggest based on more or less "scientific" conclusions.

This "institutionalist" approach contrasts with the "technocratic" one in many respects. It is primarily about the institutional procedures and governance of collective decision making, about democratic deliberation and negotiation, and about ethical commitments; and only secondarily about the analytical and computational activities conducted by natural scientists and economists. In this view, Mark Sagoff argues, economics still has a role: "It may assist society by suggesting new institutional arrangements through which people may make the bargains that may now elude them" (Sagoff 2008, 26). That is to say, it may "show society how to redesign institutions"; how to facilitate communication, deliberation and search processes; and how "to lower transaction costs that burden voluntary exchange".

Once the alternatives suggested by Nobbs are de-homogenized, the picture becomes clearer. It is important to note the undeniable tensions, gaps and incongruities between these approaches. Integrating all three into an economics of the 21 st century seems to be a tall order, a genuine challenge. Nobbs's book itself, with its vacillation between them, is an excellent illustration and warning of the difficulties involved. Yet Nobbs ends his book in a rather confident tone, heralding the rise of "ecological economics" as "part of the nascent science of sustainability", a compounded discipline that manages to both "couple the economy to society" and acknowledge human society "as an essential component of the natural ecosystem", thus coupling the economy to nature (p. 223). But, as indicated, reconciling such different approaches under an overarching conceptual and programmatic framework is a project that has to overcome serious philosophical, epistemological and methodological obstacles. As far as one can see, the track record of 
similar attempts in the history of the sciences is rather discouraging, indicating slim chances of success.

And thus we are left with a rather interesting alternative. What if, in looking toward the economics of the 21st century, we try to think more in terms of diversity than in terms of unity? Instead of a paradigm of convergence (be it based on "efficiency", "evolutionary equilibria", or "sustainability") we might try to imagine a heterogeneous field of competing and complementary approaches. Instead of one economics for the 21st century, we might think of multiple schools of thought operating in an environment defined by nested, overlapping, epistemic communities and institutional infrastructures: an institutionalized social knowledge process based on a search strategy capitalizing on the strengths coming from the combined diversity of the perspectives, approaches and methods involved.

Nobbs's book helps us better understand the current landscape of contemporary economics and its intellectual vicinity, while outlining a thought-provoking proposal about how we should be thinking and doing economics in the 21st century. Yet at the same time the book sets the stage for an informed discussion about the variety of possible alternatives that may not take the direction Nobbs advocates.

\section{REFERENCES}

Costanza, Robert. 1989. What is ecological economics? Ecological Economics, 1 (1): 1-7.

Knight, Jack, and James Johnson. 2011. The priority of democracy: political consequences of pragmatism. Princeton (NJ): Princeton University Press.

Levin, Simon. 1999. Towards a science of ecological management. Conservation Ecology, 3 (2): 6-9.

Sagoff, Mark. 2008 [1988]. The economy of the earth: philosophy, law, and the environment. Cambridge: Cambridge University Press.

Sagoff, Mark. 2012. The rise and fall of ecological economics. The Breakthrough Journal, 3 (1): 1-20.

Stavins, Robert. 2008. Environmental economics. In The New Palgrave Dictionary of Economics, eds. Steven N. Durlauf, and Lawrence E. Blume. Palgrave Macmillan.

Paul Dragos Aligica is a senior research fellow at the F. A. Hayek program for advanced study in philosophy, politics and economics, at the Mercatus Center, George Mason University. His research interests include institutional theory and normative political economy. His most recent book is Institutional diversity and political economy: the Ostroms and beyond (Oxford University Press, 2013).

Contact e-mail: <pdragos@mercatus.gmu.edu> 